\title{
As duas cidades
}

\author{
Wilton Medeiros*
}

\begin{abstract}
R esumo: A "decifração" da cidade inclui todas as possibilidades de conhecê-la. A cidade pode ser entendida como referenciadbra de sentidb altural-existencial-vivencial, pode ser entendida também como dbjeto de estudb, inteligibilidade, dbjeto planificável. O estudb das memórias de pioneiros e antigos moradbres relativiza o enfoque incisivo presente/ futuro predominante na visão modemista, desfragmentando descontinuidades e rupturas que possibilitam decodificar a cidade do passadb e codificar a cidade db presente, incluindb o conhecimento de interaçães pessoais que configuram espaços e formas existentes na imagem da cidade que vislumbramos.

Palavr as-chave: cidade; memória; desfragmentação; patrimônio.
\end{abstract}

\section{Introdução: Descortinando cidades}

0 conceito de memória coletiva de $M$ aurice Halbwachs é, efetivamente, o norteador da presente proposta de compreensão de cidades. M emórias de pioneiros e antigos moradores da cidade de Goiânia possibilitam o acesso às imagens do passado, imagens que resultam constituídas por valores de ordem social, comunicando um ethos completamente diferente do que vivenciamos no presente da imagem da cidade moderna, uma revisitação à forma de Lewis M unford entender o que é imagem da cidade, que dizia: "[...] precisamos de uma nova imagem da ordem, que abrangerá o orgânico e o pessoal; [...] somente se pudermos projetar essa imagem, seremos capazes de encontrar uma nova forma para a cidade" (M unford, 1998, p. 10).

Trata-se de uma contextualização teórica etnográfica que possibilita pensar a cidade moderna pela lente do "novo patrimônio", ou das "memórias do social" (Jeudy, 1990), possibilitando imagens do passado que se presentificam

\footnotetext{
* Mestre em Gestão do Patrimônio Cultural pela UCG e pesquisador da UEG.E-mail: wilton@ueg.br e wilton. medeiros@pop.com.br
}

na medida em que as narrativas dos pionei rose antigos moradores desfragmentam os monumentos da modernidade, construindo uma nova imagem da cidade.

Desfragmentando as imagens da cidade moderna pela lente do "novo patrimônio" ou das memórias do social, na perspectiva de uma prática de conhecimento do espaço-tempo da cultura local, percebo que a nova imagem da cidade não é composta exclusivamente de elementos físicos, imóveis, pois rever a imagem da cidade, através da lente do "novo patrimônio", é rever também a imagem da cidadania. Descortina-se assim a imagem de duas cidades: a "cidade tecnológica e a cidade antropológica", pois, muito além de formas, texturas edimensões físicas, a imagem da cidade é resultado também de uma grande diversidade de espaços e de lugares de memória (Pollak, 1989, p. 3).

\section{$M$ ais que tecnológica}

A o pensar o espaço urbano de Goiânia, se faz necessário, a princípio, pensar o seu centro, pois é para lá que apontam as suas origens históricas e políticas, que afinal se configuraram 
em conteúdo socioespacial-cultural de seu planejamento inicial. 0 ponto de origem de uma cidade, enquanto elemento de referência da cultura local, tem, talvez, maior rel evância "que as necessidades de ordem mais prática, ao fazer com que procurasse um local fixo de encontro a afinal um ponto contínuo defixação" (M unford, 1998, p. 12-13). Portanto, considero "a subjetividade do mundo simbólico como importante metodologia para se compreender a cidade" (M edeiros, 2003, p. 1), também como conhecimento para melhor intervir por meio de planejamentos (B ernardes, 1998).

O conteúdo das memórias de pioneiros e antigos moradores descortina, por detrás da "cidade tecnológica" do presente, uma outra cidade, uma "cidade antropológica", cultural, semiótica (D orfles, 2000). Por isso, o presente artigo propõe pensar Goiânia por um viés que não raro entremeia-se às questões de arquitetura e urbanismo, patrimônio, memória eidentidade. A liás, Evaldo Coutinho já deixava claro ao falar sobre "o espaço da arquitetura", que não sendo representação, mas pura realidade, só o é de fato arquitetural quanto se completa na relação entre sujeito e objeto (uma relação antropológica, eu diria):

0 espaço aberto não possui nenhuma demarcação intransponível, caracterizando-se, ao inverso das outras artes cujas obras não se deixam penetrar por ninguém; a sua condição mesma é a de fazer-se franqueável, convertendo, a quem o penetra, em participador da própria essência espacial. [...] A colaboração direta do habitante ou do mero visitante, consistente na estada de seu vulto que, em última análise, é também um valor arquitetônico. (Coutinho, 1998, p. 38-39)

Considerações sobre a "identidade art déco de Goiânia"

Sete décadas depois da criação de Goiânia, coincidentemente após a titulação da cidade de Goiás (GO) como Patrimônio da H umanidade pela U nesco, tanto o plano urbanístico quanto 0 estilo art déco, porém, mais especificamente 0 estilo art déco, passam a caracterizar o que Hobsbawn (1984) chama de invenção das tradições, um discurso empregado pelos que atualmente estão preocupados em gerir o patrimônio cultural goianiense, procurando configurar uma identidade específica, uma especificidade identitária local. Os goianienses voltam-se ao passado como uma maneira de reafirmar a identidade de Goiânia enquanto capital do estado e reafirmam a identidade goianiense pelo recurso da tradição "inventada".

A tual mente, o estilo art déco é conteúdo e referência obrigatória quando pensamos em uma discussão acadêmica sobre o que é patrimônio, também para discutir o passado da cidade de Goiânia. Leia-se o patrimônio cultural de Goiânia. Essa volta ao passado, tendo como acessibilidade uma tradição recentemente inventada, pode ser também compreendida como a criação de uma "reserva simbólica" (Porto, 1997, p. 25) da sociedade em questão. M ediada por sua "reserva simbólica", a sociedade consegue repensar o seu futuro. Por meio de "tradições inventadas", vol ta-se ao passado para instaurar o que se deseja no futuro.

Centro de Goiânia, memórias e identidades

Em paralelo ao discurso sobre 0 art déco de $G$ oiânia, a pesquisa com os seus pionei ros e antigos moradores revela que, por detrás de uma "cidade tecnológica" - uma cidade cuja obsessão é se construir moderna e futurista - , se descortinava uma "cidade antropológica" , ou seja, uma cidade desenhada por traços do ethos cultural, de valores que se configuram como tradições de grupos sociais, ou de "comunidades de memória". Percebia que, além da "identidade art déco", presente na arquitetura de várias edificações sobreviventes dos anos iniciais da construção da cidade, e por isso tombadas e geridas como seu patrimônio histórico, descortinava-se também uma multiplicidade de identidades da cidade que referenciavam, isto sim, valores vividos, construídos no cotidiano, identidades essas que nem sempre são lembradas numa política patrimonial que serve de base ideológica para definir a identidade pública da cidade. 0 que arde no fogo da memória?

Referenciado na temática memória - não a memória oficial, objetiva, mas uma memória coletiva, subjetiva (Le Goff, 1996) -, busco 
entender e visualizar a Goiânia das duas décadas iniciais, entre os anos 30 e 50, a partir de entrevistas com pioneiros. É um ol har sobre 0 passado de Goiânia com base em memórias fragmentadas e em reminiscências de velhos que nos ajudam a entender a fragmentação da paisagem urbana atual. Trata-se de um olhar sobre o que restou da "memória enquadrada" (Pollak, 1989).

Os estilhaços ou fragmentos de "memórias enquadradas" nos proporcionam um exercício de reflexão que nos remetem ao discurso do patrimônio cultural muito mais como pertencente ao domínio da "política da memória", da memória objetiva e oficial, do que das memórias subjetivas de pioneiros. A história oficial e a memória popular travam uma batalha de reminiscências que, ouvidas atentamente, desenham uma linha divisória entre o público e o privado, o oficial e 0 oficioso. É uma constatação de que os lugares de memória se transformaram em fragmentos de modernidade, cumprimento da sina de deslocamentos e mudanças na cidade angustiada pela velocidade. A memória dos pioneiros e antigos moradores luta angustiada para sobreviver. Quais políticas públicas considerarão 0 vivido para pensar o planejado? 0 estado e suas memórias formatam um trabal ho constante de configuração e de readaptação de discursos e de atos de poder.

\section{Fragmentos e memórias}

0 "trabalho" da memória reconstitui fragmentos de passado entremeados a fragmentos de presente. Ao falarem do passado da cidade, ao narrarem o seu dia-a-dia nos anos iniciais da cidade, os pioneiros e antigos moradores constroem um pano de fundo, um contraponto que reaviva a imagem do presente fragmentado e estigmatizado pelas marcas digitais da moderni dade. É importante observar, portanto, que a memória fundamentalmente "trabal ha" o presente com subjetividade. Tal subjetividade, tanto do ol har quanto da fala, calcada está sobre um passado de inúmeros pequenos registros que dialogam fundamental mente com o presente, refere-se ao presente, e não estrita e exclusivamente ao passado, como poderíamos supor.
Os fios de memórias tecidos pelas narrativas de pioneiros e antigos moradores nos conduzem a lugares e comunidades de memória. Seguir esses fios de memória é buscar a trama que constitui a "cidade antropológica", muitas vezes escondida sob conurbações, arrefecidas sob as ilhas de calor, ou mesmo acanhada por entre manchas de poluições visuais, olfativas, auditivas.

M emória, passado e patrimônio são categorias que emergem de construções ideológicas ou representações coletivas (Cardoso de Oliveira, 1976) e que legitimam a existência ou atuação de atores ou grupos sociais. Coletar por meio de entrevistas as memórias dos moradores do Centro de Goiânia nas suas décadas iniciais significa entrar em contato com fatos, imagens, lugares, feitos que se encontram na ordem do coletivo, e somente como tal têm sentido. Por isso, as narrativas, ainda que coletadas individualmente, se entrecruzam no coletivo. $M$ as isso também não quer dizer que as décadas iniciais do Centro de Goiânia produziram uma memória coletiva homogênea. A fragmentação da paisagem do presente de certa forma é reveladora da diversidade de interesses sobre a cidade. Da diversidade de "memórias coletivas". Portanto, longe de uma memória coletiva homogênea, oficial, temos isto sim uma diversidade muito grande de memórias. Daí a diferença entre o patrimônio cultural oficial, que busca construir uma memória homogênea e límpida como instrumento de legitimação de poder político, e a memória coletiva, composta de memórias fragmentadas que explicam a paisagem fragmentada do presente.

A paisagem urbana que deparamos atualmente no Centro de Goiânia é também conseqüência da diversidade de memórias coletivas com seus jogos de poderes a definir o que deve ser lembrado e o que deve ser apagado da lembrança. A sociedade gesta o seu patrimônio cultural na medida ou na forma em queéconstruído também o seu "poder simbólico" (B ourdieu, 1989). A s lembranças são negociações para construir simbolicamente o presente. Para M ilton Santos, "tanto a pai sagem quanto 0 espaço resultam de movimentos superficiais e de fundo da sociedade" (1988). 


\section{Construindo desfragmentações}

Com relação à assertiva de que a cidade deve ser vista como algo não coisificado, material, privilegiando o subjetivo e imaterial, Silva (1998) apresenta idéias referenciadoras:

0 discurso sobre a cidade tende, por vezes, a configurar sua identidade num plano de materialidade extra-humana - ou humana desde que a maior parte dos homens esteja excluída dessa categoria. É assim que a cidade a ser vista como conjunto de edificações perturbadoramente esvaziadas de seus construtores, habitantes e permanentes inventores. Essa cidade fossilizada, paródia das paisagens do pintor metafísico De Chirico, tem por efeito a coisificação de Patrimônio e História, fazendoos mergulhar no tempo vazio e homogêneo de quefal ou B enjamin.

[...] N esse sentido, o debate sobre Patrimônio Histórico extrapola a restrição ao edificado, englobando tanto diferentes artefatos (objetos de uso cotidiano da população, lembranças de múltiplas experiências etc.) como saberes daquelas pessoas e - por que não? - elas mesmas. (Silva, 1998 p. 58-59)

A s imagens da cidade de Goiânia, tanto a atual quanto a dos anos iniciais, construídas com base em entrevistas e depoimentos, configuram a memória do presente e a memória do passado que se presentifica. São imagens que reconstroem os construtores da cidade, muito mais do que as construções materiais que formam 0 tecido urbano. Não dependem do instituto do tombamento, da monumentalidade e do estilo das edificações. Sem se preocupar com o sentido da história, com o "fazer história", ou com a construção da modernidade, trazem ao presente fatos e vivências dos "quadros sociais da memória" (Halbwachs, 1990).

As memórias "desinteressadas", como as de Seu Otagamis (Fig. 1), nos possibilitam também múltiplas contraposições ejustaposições acerca de como percebem coletivamente 0 espaço e o tempo no cotidiano.

Coletar por meio de entrevistas as memórias dos antigos moradores de Goiânia, ter a experiência de ouvir as narrativas sobre as décadas iniciais do que hoje conhecemos por Centro de Goiânia, significa entrar em contato

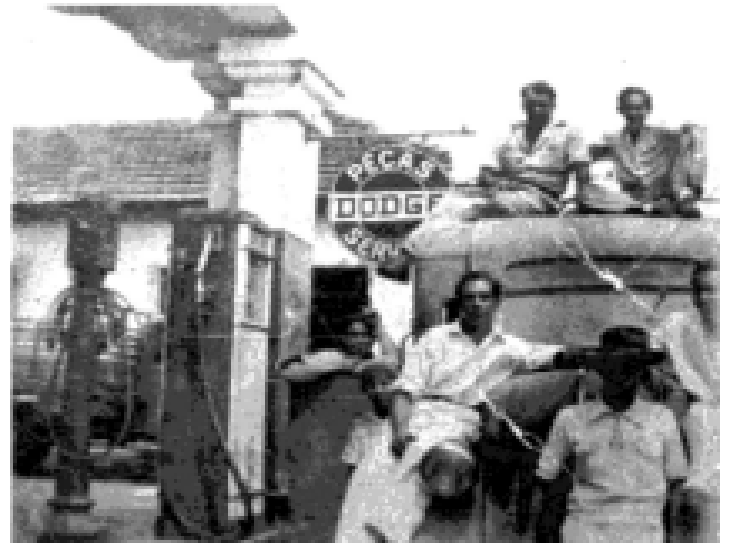

Figura 1 - Antigo Posto de Gasolina na A venida Anhangüiera. (Seu Otagamis)

com fatos, imagens, lugares, feitos que se encontram na ordem do coletivo, e somente como tal têm sentido. $E$ é essa experiência com o coletivo que dá o sentido do todo, também 0 sentido da partici pação e pertencimento do todo.

0 sentido do todo - evocado nas lembranças, na imagem da cidade do passado e experimentado pelo indivíduo ao pertencer à col etividade - pode reconstruir a imagem da cidade no presente.

No todo fragmentado da cidade de Goiânia, o Parthenon Center (Figs. 2 e 3) é apenas mais um fragmento. Entretanto, quando ouvimos relatos que 0 incluem no dia-a-dia de pessoas comuns, a história da cidade de Goiânia é vulcanizada por trechos de memória que ressemantizam a forma e a função dos edifícios, redirecionando o "sentido de existir" resgatado pela "rede de significados" dos fios que tecem a cultura.

A o ouvirmos narrativas que religam 0 Parthenon Center, edificação marcante na paisagem do Centro de Goiânia, podemos nos deparar com o que denomino aqui de desfragmentação. A desfragmentação ocorre quando ouvimos narrativas que "religam" a individualidade do elemento edificado, constante no presente da cidade, ao tecido da memória a partir da reconstrução de relatos. A ssim, 0 Parthenon Center é identificado em testemunhos do passado, bem como edificações antigas existentes em seu entorno, relacionando-os à lembrança do que era o $M$ ercado $M$ unicipal, uma das primeiras edificações públicas, que foi 

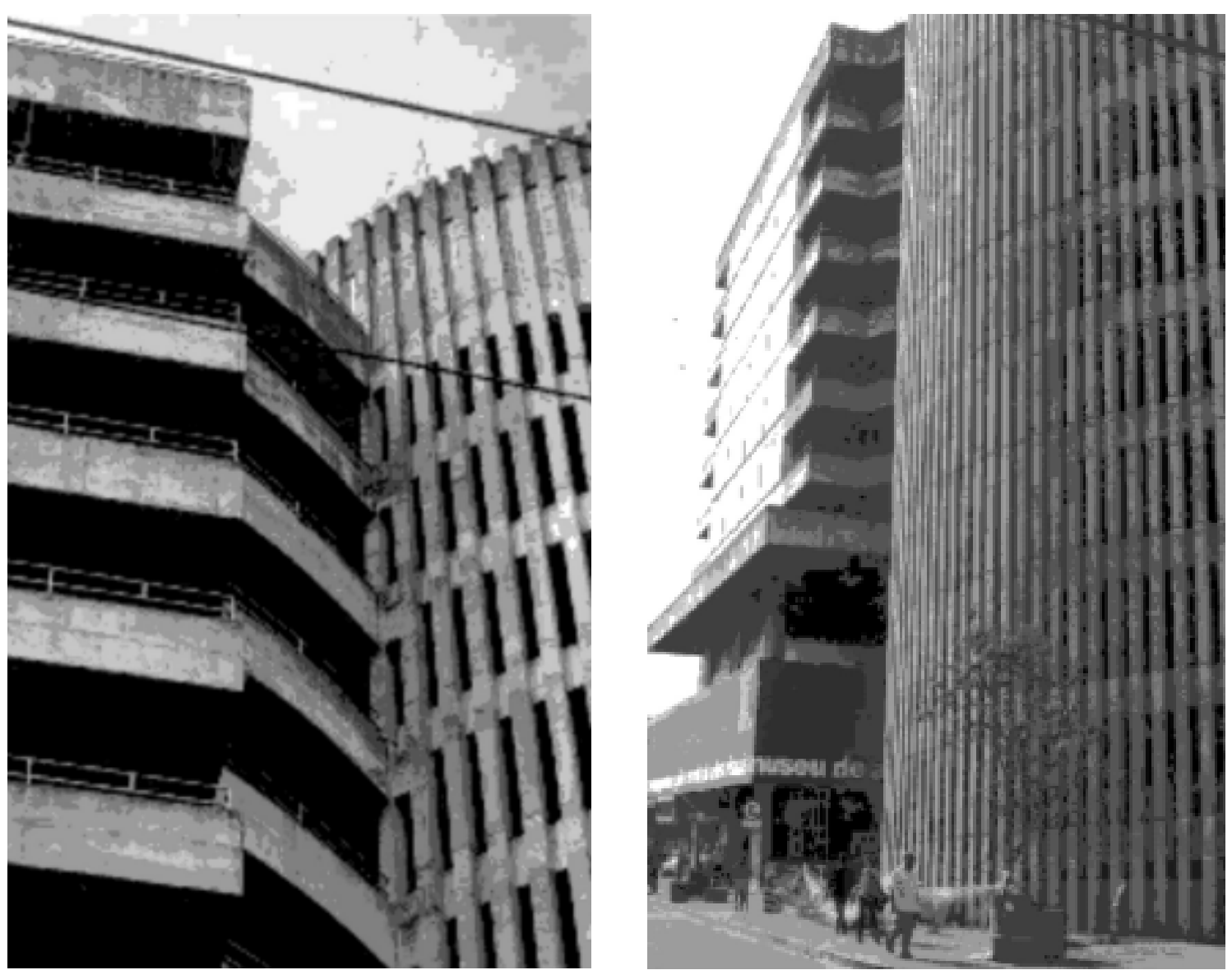

Figuras 2 e 3 - F achadas do Parthenon Center, edifício localizado na Rua 4. (Fernanda Rezende)

demolida para dar lugar exatamente à construção do Parthenon Center. Ouvindo as narrativas que colocam o extinto $M$ ercado $M$ unicipal como importante lugar de memória, os fragmentos do passado localizados em seu entorno passam a ter sentido no presente, conforme os depoimentos abaixo:

Tinha o mercado! 0 M ercado Central, onde éo Parthenon Center. Era o mercado né, era 0 mercado ali, tinha tudo. Todo mundo se encontrava no mercado, no mercado. De manhã. Todo mundo fazia compras lá. Verduras, frutas, carne... (B enedita Chaves de Oliveira - junho/ 2002)

Lá, todo mundo ia. Era ali na Rua 4, naquela praça ali, onde é aquele prédio... Lá era 0 M ercado... aquele lá era antigo... (Gercino Gomes de Paula - setembro/2002)

Era uma das nossas opções, o M ercado Central, porque armazém mesmo, não havia. Tinha uma padaria... tinha uma padaria na $\mathrm{R}$ ua 6 , de frente pro M ercado Central, descendo a Rua 6, tinha essa padaria... (A rmênia P. Souza - setembro/ 2002)

O M ercado Central de Goiânia é a referência fulcral das narrativas de Seu J osé M endonça Ribeiro, que lá trabalhou desde 1950 até a sua demolição para dar lugar à construção do Parthenon Center.

Todo mundo ia. Naquele tempo, era ótimo o mercado, porque só tinha um mercado, não, tinha outro mercado em G oiânia, não existia um supermercado, não só tinha um mercado. [...] Para o pobre, para o rico, para o médio, tinha. Tinha dia de nós vender 25 sacos de arroz na concha, dia de sábado. [...] De domingo a domingo. Só fechava Sexta-Feira da Paixão e dia de eleição.

[...] 0 primeiro mercado, primitivo, tinha muita madei ra, e era uma construção mais rústica, mas erabom. 
[...] Você via ao redor do M ercado, no U muarama Hotel, ali tudo era lugar de descarga, de bebedouro pra tropa. [...] Chegava no mercado, tinha vinte, trinta charrete esperando aí pra pegar freguês. [...] Você podia contar trinta, quarenta charrete, naquele tempo.

[...] De lá nós mudamos para o segundo mercado, [...] aqui para a Rua 4-A , uma pequena rua. Nós ficamos encurralados, ali. Era uma dificuldade tremenda para a carga e descarga, porque não tinha espaço. [...] A quilo foi política! [...] 0 U muarama construiu aquele hotel grande, e o U muarama tinha um despeito de o hotel ser em frente de um mercado daquele. (José $M$. Ribeiro - setembro/2002)

A desfragmentação de elementos modernos dispersos promove uma rejunção do tecido das memórias que nos possibilita uma nova imagem global da cidade. Então, sair do local em direção ao global, como numa atividade de interpretação antropológica, foi o que aconteceu na medida em que aumentavam a quantidade e a diversidade de depoimentos e entrevistas de antigos moradores de Goiânia. Percebi que essa gradação ou esse movimento em direção a um "todo" se dava na medida em que as incongruências dos fragmentos existentes no presente, em se "trabalhando" a memória, conferiam "presença ao passado para dar significado ao presente" (Woortmann, 1998).

A imagem que a "Goiânia antiga" suscita nos relatos dos moradores antigos é a imagem de um todo que perfaz "a cidade", uma imagem global. I sso talvez se explique por que a "Goiânia antiga" era vista e vivida como "uma cidade pequena" (Oliveira, 2002, p. 11).

A percepção da cidade como um todo, globalmente, também era possibilitada pela inexistência de barreiras naturais e favorecida por uma preponderante horizontalidade das edificações. Durante as décadas iniciais de Goiânia, apesar de permitida a construção de edifícios até oito pavimentos, sobressaía-se a horizontalidade, com edifícios de no máximo três pavimentos.

A s narrativas e o "mapa da memória" (Fig. 4), de Henrique de Freitas, que viveu a sua adolescência em Goiânia antes que a cidade ganhasse feições de cidade grande, sintetizam a imagem da Goiânia antiga. Representa com

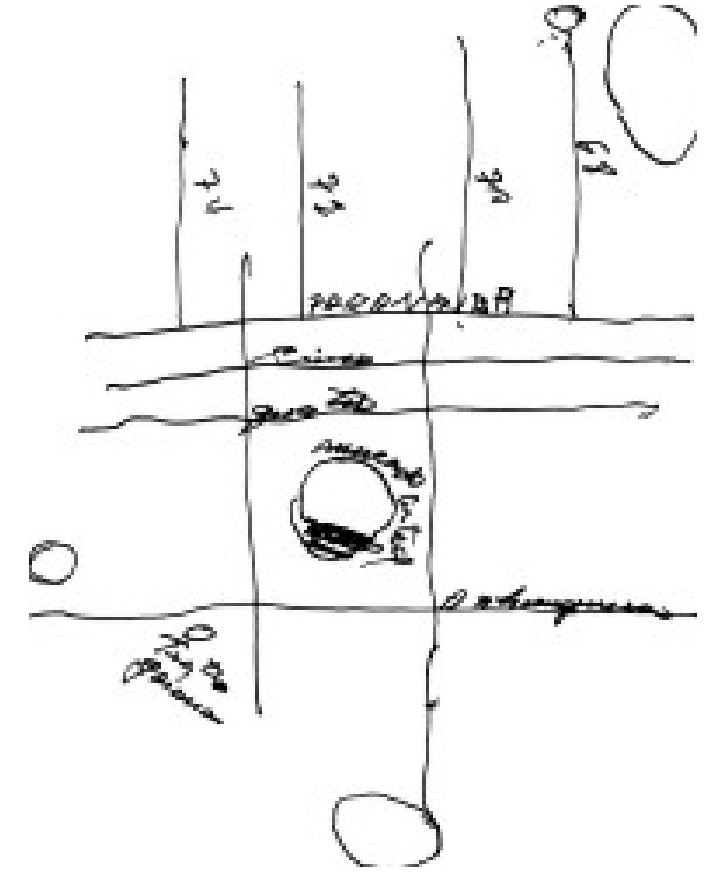

Figura 4 - Mapa da Memória. (Henrique de Freitas)

clareza que os limites da cidade, naquele período, ainda eram o rio e o mato. Isso fica bem claro em seu desenho, quando representa a cidade de vermelho e os seus limites de verde (o mato) e azul (o rio).

Eu mudei de G oiânia com 18 anos de idade, fui morar fora, por mais de década. E quando eu saí, apesar de ter presenciado, vivenciado esse "segundo fluxo desenvolvimentista de Goiânia", que é a questão da implantação da arquitetura modernista, dos prédios residenciais no Centro de Goiânia, o começo da expansão do Setor Oeste, essas coisas em 80 , Goiânia ainda era uma cidade do interior. A inda era considerada, ou ainda era sentida como tal. Sim, porque você cruzava Goiânia em vinte minutos. (Henrique de F reitas - setembro/2002)

\section{Consider ações finais}

As memórias não são anônimas. As memórias, como as pessoas, têm identidade, fazem parte de grupos sociais. G rupos sociais que permanecem e por isso se referenciam na memória. $\mathrm{Na}$ medida em que reconstruímos a paisagem do passado com base em depoimentos dos pioneiros, percebemos que eles formam uma "comunidade de memória" (Borjas, 1995). A 
"comunidade de memória" lembra e esquece em conjunto. É o que Lovisolo (1989) chama de "retórica da memória". É preciso "negociar a memória" para que ela se torne coletiva:

Para que nossa memória se beneficie da dos outros, não basta que eles nos tragam seus testemunhos: é preciso também que ela não tenha deixado de concordar com suas memórias e que haja suficientes pontos de contato entre ela e as outras para que a lembrança que os outros nos trazem possa ser reconstruída sobre uma base comum. (Halbwachs, apud Pollak, 1989)

0 passado não tem significado al gum para os ambulantes ou transeuntes que circulam no comércio daA venida A nhangüera hoje. M esmo o discurso do art déco como identidade goianiense é al go rel ativamente recente, que tem como influência o valor que a "elite turística" tem dado ao passado.

A paisagem verticalizada, a Goiânia modificada, não foi um processo que ocorreu em separado à vivência daqueles pioneiros. Os mesmos ocupantes dos lotes e residências iniciais de Goiânia são também os primeiros compradores de escritórios e apartamentos em novas edificações verticais. Com base na análise de suas narrativas, podemos repensar as políticas do patrimônio cultural em Goiânia, perceber que o passado da cidade, sob domínio público, pertence hoje a todos os seus habitantes, cuja referência são os seus pioneiros.

\footnotetext{
A bstract: The "deciphering" of the city includes all the possibilities of knowing it. The city could be understood as the reference of the alltural-existential and sense of life. It could be understood as on dbject of study, of intelligibility an object of stuoly, of intelligibility a planificável dbject. The study relativist of the pioneers and of the antique inhabitants memoirs account the incisive view point of the present and the future predominant in the modemist view, destroying the discontinuations and the ruptures that will be able to decode the city of the present including the knowledge of personals interactions that represent spaces and shapes that exist in the image of the city that we realize.
}

K ey words: city; memory; defragmantation; inheritance.

\section{Referências}

BERNARDES, Genilda Darc. Goiânia: cidade planejada/cidade vivida - discurso e cultura da modernidade. 1998. Dissertação (M estrado) - UnB, Brasília.

BORJAS, M anuel Chaves. Comunidad de memória: memória metafórica de uma localidad en el sertão brasileño. 1998. Tese (D outorado em A ntropologia) - UnB, B rasília.

B OURDIEU, Pierre. 1989.0 poder simbólico. Rio de J aneiro: Ed B ertrand B rasil, 1989.

CARDOSO DE OLIVEIRA, Roberto. Identidade, etnia e estrutura social. São Paulo: Livraria Pioneira, 1976.

CERTEA U, M ichel de. A ndando na cidade. Revista do Patrimônio Histórico e Artístico Nacional. B rasília: I phan, 1994.

COUTIN HO, Evaldo. 0 espaço da arquitetura. São Paulo: Ed. Perspectiva, 1998.

DORFLES, Gilles. Arquitetura moderna. São Paulo, 2000

GEERTZ, Clifford. A interpretação das culturas. Rio de Janeiro: Zahar, 1978.

HOBSBAWN, E \& RANGER T. A invenção das tradições. Petrópolis: Paz eTerra, 1984.

HA L BWA CHS, M aurice. A memória coletiva. São Paulo: V értice, 1990.

JEUDY, Piere. M emórias do social. Rio de J aneiro: Forense U niversitária, 1990.

LE GOFF, Jacques. História e memória. Campinas: Ed. da U nicamp, 1996.

L OVISOLO , H. A memória e aformação dos homens. Estudos $\mathrm{H}$ istóricos. Rio de Janeiro. v. 2, n. 3, Fundação G etúlio Vargas, 1989.

LOWENTHAL, D. El pasado es un país extraño. $M$ adrid: Ediciones A kal, 1998.

MEDEIROS, W. A . Patrimônio, memória e gestão: uma nova imagem de Goiânia. 2003. Dissertação (M estrado) - UCG, Goiânia.

. Centro de $G$ oiânia, memórias e identidades. Ėstudos/Humanidades. v. 30, n. 3, mar. 2003, G oiânia: Ed.UCG.

MUNFORD, Lewis. A cidade na história. Goiânia: $M$ artins Fontes, 1998.

OLIVEIRA, E. Cardoso de. História cultural de G oiânia. Goiânia: A gepel/U EG 2002.

POLLAK, M ichael. M emória, esquecimento, silêncio. Estudos Históricos, v. 2, n. 3, Rio de Janeiro, 1989. 
- M emória e identidade social. E studos H istóricos, v. 5, Rio de Janeiro, 1992.

PORTO, Liliana de M endonça. A reapropriação da tradição a partir do presente: um estudo sobre a festa de N . Sa do R osário de C hapada do N orte/M G . Dissertação (M estrado) - UnB, B rasília.

SANTOS, M ilton. M etamorfoses do espaço habitado. São Paulo: Hucitec, 1988.

SILVA, Marcos A. da. Fantasia e função. In: A construção da cidade. Distrito Federal: B rasília, 1997.
W OORTM AN, Ellen F. H omens de hoje, mulheres de ontem - gênero e memória no seringal. In: I SEM INÁRIO ElI SEMANA DE ANTROPOLOGIA DA UNIVERSIDADE CATÓLICA DE GOIÁS. Anais... Goiânia: Ed. UCG , 1998.

Recebido em dezembro de 2002 A provado em Julho de 2003 